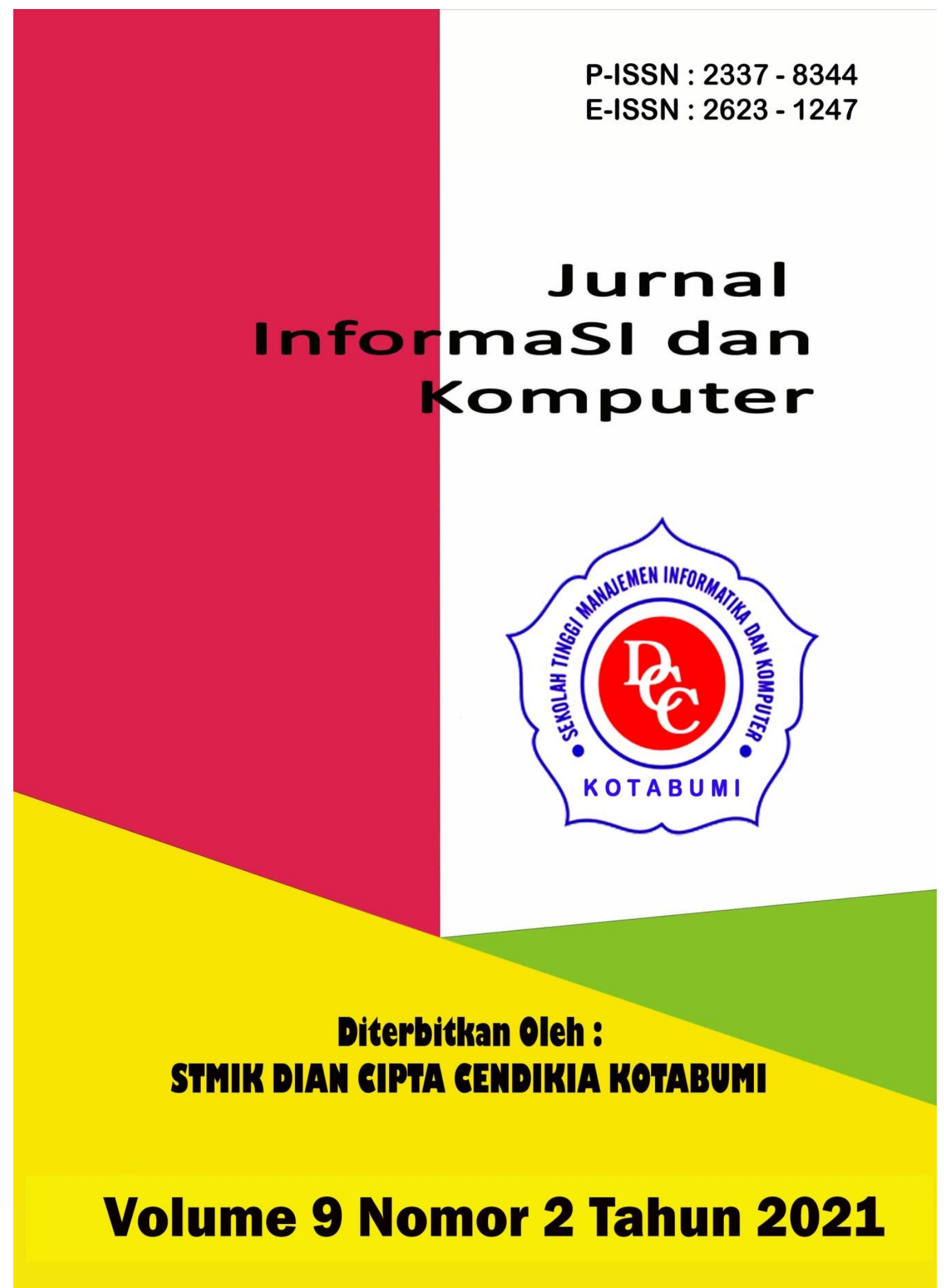




\section{Penerbit}

\section{Lembaga Penelitian STMIK Dian Cipta Cendikia Kotabumi}

Hak atas naskahh/tulisan tetap berada pada penulis, isi diluar tangung jawab penerbit dan Dewan Penyunting 


\section{PENGANTAR REDAKSI}

Puji syukur dipanjatkan kehadirat Tuhan Yang Maha Esa, atas karunia dan limpahan rahmatNYA jualah Jurnal Informasi dan komputer (JIK) STMIK Dian Cipta Cendikia Kotabumi ini dapat terwujud.Jurnal Informasi dan Komputer (JIK) yang terbit dua (2) kali dalam setahun ini merupakan suatu wadah untuk penyebar luasan hasil-hasil penelitian, studi pustaka, karya ilmiah yang berkaitan dengan Informasi dan Komputer khususnya bagi dosen-dosen STMIK Dian Cipta Cendikia Kotabumi serta umumnya para cendikiawan, praktisi, peneliti ilmu Informatika dan Komputer.

Harapan, dengan diterbitkannya Jurnal Informasi dan Komputer (JIK) ini sebagai salah satu bentuk sumbangan pemikiran dalam pengembangan ilmu informatika dan komputer yang berkaitan dengan kajian-kajian di bidang tekhnologi Informatik, Komunikasi Data dan Jaringan Komputer, perancangan dan Rekayasa Perangkat Lunak, serta ilmu-ilmu yang terkait dengan bidang Informasi dan Komputer lainnya.

Berkenaan dengan harapan tersebut, kepada para peneliti, dosen dan praktisi yang memiliki hasil-hasil penelitian, kajian pustaka, karya ilmiah dalam bidang tersebut diatas, dengan bangga redaksi Jurnal Informasi dan Komputer (JIK) menerima naskah ringkasan untuk dimuat pada jurnal Informasi dan Komputer (JIK) STMIK Dian Cipta Cendikia Kotabumi dengan berpedoman pada penulisan naskah jurnal sebagaimana dilampirkan pada halaman belakang (Bagian kulit dalam) buku jurnal ini.

Mutu dari suatu jurnal ilmiah tidak hanya ditentukan oleh para pengelolanya saja, tetapi para penulis dan pembaca jualah yang mempunyai peranan besar dalam meningkatkan mutu jurnal Informatika dan Komputer ini. Merujuk pada realita ini kamu sangat mengharapkan peran aktif dari peneliti untuk bersama-sama menjaga dan memelihara keberlangsungan dari jurnal Informasi dan Komputer STMIK Dian Cipta Cendikia Kotabumi ini. Yang juga tidak kalah pentingnya dari partisipasi tersebut diatas, adalah saran dan kritik yang membangun dari pembaca yang budiman agar kiranya dapat disampaikan langsung kepada redaksi JIK. Saran dan kritik yang membangun akan dijadikan masukan dan pertimbangan yang sangat berarti guna peningkatan mutu dan kualitas Jurnal Informasi dan Komputer STMIK Dian Cipta Cendikia Kotabumi.

Tak lupa diucapkan terima kasih yang tak terhingga atas perhatian dan kerjasama dari semua pihak yang tak dapat disebutkan satu persatu hingga dapat diterbitkan nya Jurnal Informasi dan Komputer (JIK) STMIK Dian Cipta Cendikia Kotabumi. Semoga apa yang telah diperbuat untuk kebaikan akan menjadi amal ibadah, amin.

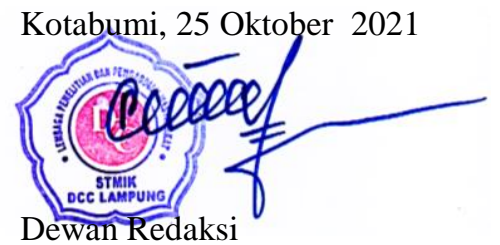




\section{JURNAL INFORMASI DAN KOMPUTER}

Volume 9 Nomor 2 Oktober 2021

Jurnal Informasi dan Komputer merupakan Sarana informasi ilmu pengetahuan, Tekhnologi dan Komunikasi yang berupa hasil penelitian, tulisan ilmiah, Ataupun studi pustaka. Jurnal ini terbit dua kali setahun pada bulan April dan Oktober. Berisi hasil penelitian ilmiah di bidang informatika yang bertujuan untuk menghubungkan adanya kesenjangan antar kemajuan teknologi dan hasil penelitian. Jurnal ini di terbitkan pertama kali pada tahun 2013.

Penanggung Jawab:

Ketua STMIK Dian Cipta Cendikia Kotabumi

\section{Pembina:}

Ketua STMIK Dian Cipta Cendikia Kotabumi Ketua Lembaga Penelitian STMIK Dian Cipta Cendikia Kotabumi

\section{Pimpinan Redaksi}

Dwi Marisa Efendi,.S.Kom.,M.Ti

\section{Redaksi pelaksana}

Rustam,.S.Kom,.M.Ti (STMIK Dian Cipta Cendikia Kotabumi)

Nurmayanti M.Kom (STMIK Dian Cipta Cendikia Kotabumi)

Sukatmi,.S.Kom., M.Kom (AMIK DCC Bandar Lampung)

Sampurna Dadi Riskiono,M.Kom (Universitas Teknokrat Indonesia)

Ifo Wahyu Pratama,S.Kom.,M.Ti(AMIK MASTER Lampung)

\section{Mitra Bestari}

Dr. RZ. ABDUL AZIZ, ST., MT (Institut Informatika dan Bisnis Darmajaya)

Dr. Dadang Sudrajat, S.Si, M.Kom (STMIK IKMI Cirebon)

Dr. Septafiansyah Dwi Putra, S.T., M.T (Politeknik Negeri Lampung)

Dr. Evi Grativiani, S.E., M.S.I (Universitas Sebelas Maret)

Rohmat Indra Borman ( Universitas Teknokrat Indonesia )

Ferry Wongso, S.KOm., M.Kom ( STMIK Darma Pala Riau)

Ferly Ardhy, S.Kom., M.Ti ( Universitas Aisyah Pringsewu )

Firmansyah, S.E., M.Si (STMIK Darma Pala Riau)
Amarudin (Universitas Teknokrat Indonesia)

Didi Susianto, S.T., M.Kom (AMIK Dian Cipta Cendika Bandar Lampung)

Alhibarsyah, St., M.Kom (STMIK Tunas

Bangsa Bandar Lampung)

Kemal Farouq Mauladi, S.Kom .M.Kom (Universitas Islam Lamongan)

Rima Mawarni, M.Kom ( STMIK Dian Cipta Cendikia Kotabumi)

Wira Jaya Hartono, S.Pd., M.Pd ( STMIK Darma Pala Riau)

Penerbit : STMIK Dian Cipta Cendikia Kotabumi Bekerja Sama Dengan LPPM STMIK Dian Cipta Cendikia Kotabumi.

\section{Alamat Redaksi/Penerbit:}

Jl. Negara No. 3 Candimas Kotabumi Lampung Utara

No Telpon/Fax 072423003

Email : 1ppm-stmik@dcc.ac.id 


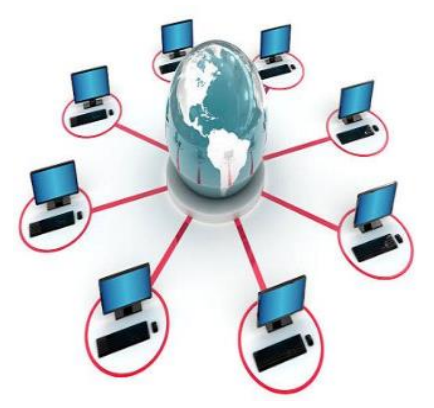

\section{JURNAL INFORMASI DAN KOMPUTER VOL. 9 NO. 2 THN. 2021}

\section{DAFTAR ISI}

Halaman

Sistem Informasi Akuntansi Persedian Barang Berbasis Web Pada Lembaga

Permasyarakatan Kelas II A Banceuy Bandung : "Kelompok Tani Desa Banjar Kertarahayu” Teuku Rian Hardiyansyah, Fatia Salsa Azzahra (Politeknik Piksi Ganesha Bandung ${ }^{1,2}$ ).

Penerapan Finite State Automata Pada Vending Machine Penjual Obat Non Resep

Dokter Dan Keperluan Medis

Eko Supriyanto $^{1}$, Angga Ardiansyah ${ }^{2}$, Frieyadie $^{3}$, Sri Rahayu ${ }^{4}$, Windu Gata ${ }^{5}$

(Universitas Nusa Mandiri ${ }^{12}$ )

Sistem Pendukung Keputusan Untuk Menentukan Kelayakan Pengajuan Sertifikasi Guru Dengan Metode Simple Additive Weighting (Studi Kasus : Ma Al Muhajirin Janti Jogoroto Jombang)

Budiman, umam baharudin, winarti

(Universitas Darul 'Ulum Jombang)

Perancangan Infrastruktur Domain Name Server Lokal Menggunakan Ubuntu Server 16.04

Pada PT. Xyz

Zaenal Mutaqin Subekti, Hendra Setiawan, Satria, Widia Murni Wijaya,

Aliy Hafiz, Warsudi

(STMIK Bani Saleh, Universitas Negeri Yogyakarta, AMIK Dian Cipta Cendikia,

STMIK MIC CIkarang)

Perancangan Sistem Informasi Idea Proposal (Ip) Berbasis Web Pada Pt. Paxel Algorita Unggul

Julian Murhan Sahputra, Indah Purnamasari

(Universitas Nusa Mandiri ${ }^{12}$ )

Sistem Pendukung Keputusan Untuk Menentukan Ekstrakurikuler Atletik

Berdasarkan Bakat Siswa Menggunakan Metode Profile Matching

Agnes Basuki, Petrus Sokibi, Tiara Eka Putri

(Universitas Catur Insan Cendekia)

Penerapan Algoritma K-Means Untuk Pengelompokan Usia Calon Penerima Vaksin

Di Kab. Ngawi

Irna Yuniarfi, Saifulloh

(Universitas PGRI Madiun ${ }^{12}$ )

System Penilaian Seleksi Calon Karyawan Baru Menggunakan Metode Simple Additive Weighting (SAW) Di PT.TNA

Anik Sri Wahyuningsih, Yudhi Firmansyah

(Universitas Panca Sakti Bekasi ) 
Perancangan Sistem Informasi Pembayaran SPP Menggunakan Framework Laravel Ichwan Habib Moudi

(Universitas Panca Sakti Bekasi)

Implementasi Algoritma K-Means Dan Algoritma Apriori Optimasi Kinerja Ecu

(Study Kasus Mobil Avanza Dan Xenia)

Sigit Mintoro' Asep Afandi

(STMIK Dian Cipta Cendikia Kotabumi)

Sistem Pakar Penyakit Buah Kakao Untuk Peningkatan Hasil Panen Kakao Menggunakan

Metode Case Base Reasoning (CBR) Berbasis Web Mobile

Aliy hafiz, Verawati

(AMIK Dian Cipta Cendikia,Bandar Lampung)

Penerapan Metode Rapid Application Develomment (RAD) Dalam Pengembangan

Sistem Pemesanan Menu Berbasis Android

Aris Baihaqi, Tumini

(Fakultas Sains dan Teknologi ${ }^{1,2}$ )

Rancang Bangun Sistem Informasi Geografis Pariwisata Di Lampung Timur

Sukatmi, Rexa Alfa Rizi

(AMIK DCC Bandar Lampung ${ }^{12}$ )

Implementasi Psak No. 45 Pada Proses Penyusunan Laporan Keuangan Menggunakan

M.S. Excel Dan Aplikasi Accurate Accouting Pada STMIK Bani Saleh

Marhakim, Willy Adam

(STMIK Bani Saleh ${ }^{12}$ )

Sistem Prediksi Harga KOPI LAMBAR ( Lampung Barat) Dengan Metode

Backpropagation, dan Double Exponential ( Studi Kasus BUMDES )

Supriyanto, Dwi marisa Efendi,Rhomadhon

(STMIK Dian Cipta cendikia Kotabumi ${ }^{1-}$ )

Sistem Informasi Pemasaran Produk Umkm Berbasis Web Pada Kecamatan Bumi

Nabung Lampung Tengah

Yuli Syafitri, Agus Prasetyo, Reni Astika

(AMIK Dian Cipta Cendikia Bandar Lampung)

Rancang Bangun Aplikasi Pembelajaran Aksara Lampung Berbasis Android

Ferly Ardhy, Hendra Syahrobi

(Universitas Aisyah Pringewu ${ }^{1,}$ STMIK Dian Cipta Cendikia ${ }^{2}$ )

Sistem Pakar Diagnosa Penyakit Kulit Pada Balita Menggunakan Metode Naïve

Bayes Dan Forward Chaining Studi Kasus Puskesmas Cempaka Sungkai Selatan

Sidik Rahmatullah, Rima Mawarni

(STMIK Dian Cipta Cendikia Kotabumi ${ }^{12}$ )

Rekayasa Perangkat Lunak Perhitungan Harga Pokok Produksi Metode

Full Costing Pada Umkm Mitra Cake Di Bandar Lampung

Pitrawati, Arif Sanjaya

(AMIK Dian Cipta Cendikia, Bandar Lampung) 
Rancang Bangun Sistem Ujian Online Menggunakan Algoritma Cosine Similarity

Berbasis Web

Haryono, Zaenal Mutaqin Subekti, Widiyawati, Hidayatullah

(STMIK Bani Saleh ${ }^{1234}$ )

Model Aplikasi Helpdesk Ticketing System Berbasis Web Menggunakan Metode Rad

Indra Permana

Pattern Recognition Tulisan Tangan Huruf Hijaiyah Menggunakan Metode

Convolutional Neural Network (CNN)

Mufassiril Abror, Nopiyanto

(Universitas Panca Sakti Bekasi ${ }^{12}$ )

Aplikasi Sistem Informasi Keuangan Berbasis Android Di Perumahan Taman

Karang Bahagia

Melda Ayulestari

(Universitas Panca Sakti Bekasi)

Audit Pelayanan Sistem Rujukan Online Puskesmas Menggunakan Framework COBIT 5.0

Nurmayanti, Merri Parida, Ngajiyanto, Ina Anzalna

(STMIK Dian Cipta Cendikia Kotabumi ${ }^{1234}$ )

Perancangan Sistem Informasi Pengolahan Data Nilai Siswa Berbasis Web

Erin Ermawati, Anik Sri Wahyuningsih

(Fakultas Sain dan Teknologi, Universitas Panca Sakti Bekasi ${ }^{12}$ )

Pengembangan Sistem Pelaporan Data Hasil Inspeksi Barang Berbasis Web

Siska Putriani

(Universitas Pancasakti Bekasi)

Penerapan Extreme Programming Dalam Perancangan Aplikasi Web Food Market

Tumini, Hilman Septiana

(Fakultas Sains dan Teknologi Universitas Panca Sakti Bekasi ${ }^{1,2}$ )

Sistem Pencarian Barang Berbasis Website Menggunakan Php Dan Mysql

Studi Kasus PT. Surya Technology Industri Sulaeman

(Universitas Panca Sakti Bekasi)

Implementasi Metode Prototype Pada Sistem Peminjaman Alat Kerja Berbasis Web

Di PT SK Metalindo

Ali Mulyanto, Arjun Gunawan

(Univeritas Panca Sakti Bekasi)

Aplikasi Tata Cara Wudhu Menggunakan Teknologi Augmented Reality

Sebagai Media Pembelajaran Di TK Al Fatih

Ahmad Yakub , Idarul Fadli

(Universitas Panca Sakti Bekasi ${ }^{12}$ )

Sistem Pakar Diagnosa Penyakit Ayam Petelur Menggunakan Metode Certainty Factor

Berbasis Web Mochammad

Taufiq Hidayat, Ali Mulyanto

(Universitas Panca Sakti Bekasi ${ }^{12}$ ) 
Penerapan Metode Prototyping Dalam Perhitungan Hasil Produksi Menggunakan

Arduino Uno R3 Dan Php Di PT. Indonesia Epson Industry

Amandha Aulia, Ajar Rohmanu

(Universitas Panca Sakti Bekasi ${ }^{12}$ )

System Pendukung Keputusan Penentuan Guru Teladan Dengan Metode Profile Matching

Hasbulloh, Agmawarnida

(Universitas Panca Sakti Bekasi ${ }^{1,2}$ )

Implementasi Waterfall Method Pada Aplikasi Buku Induk Siswa Berbasis Web

Idam Holid, Yogie Krisnayadi

(Universitas Panca Sakti ${ }^{12}$ )

Pengembangan Text To Speech Media Pembelajaran Untuk Pengenalan

Anggota Tubuh Manusia Kelas V Sekolah Dasar

Juwanda Saputra, Ali Mulianto

(Teknik Infomratika Fakulutas Sains dan Teknologi ${ }^{12}$ )

Perancangan Sistem Peminjaman Barang Berupa Aset Tetap Berbasis Web

Pada Lembaga Permasyarakatan Kelas II A Banceuy Bandung

Guntur Salasa Priambodo, Perwito, Candra Mecca Sufyana

(Politeknik Piksi Ganesha Bandung ${ }^{1,2,3}$ )

Metode Pemilihan Karyawan Terbaik Sebagai Penentu Goodwill Perguruan Tinggi

Dengan Menggunakan Metode Topsis (Studi Kasus Perguruan Tinggi Di Lampung Utara)

Dwi Sartika, Pakarti Riswanto

(STMIK Dian Cipta Cendikia Kotabumi)

Sistem Pendukung Keputusan Pemilihan Merek Smartphone Menggunakan

Metode Analytical Hierarchy Process (AHP)

Ade Kiki Fatmawati, Muhammad Sultan Raflie, Norma Yunita

(Universitas Nusa Mandiri ${ }^{123}$ )

Pattern Recognition Aksara Lampung Menggunakan Algoritma Neural Network

Metode Analytical Hierarchy Process (AHP)

Nopiyanto, Rahmadi

(Universitas Panca Sakti Bekasi) 


\title{
RANCANG BANGUN SISTEM INFORMASI GEOGRAFIS PARIWISATA DI LAMPUNG TIMUR
}

\author{
Sukatmi $^{1}$, Rexa Alfa Rizi ${ }^{2}$ \\ AMIK DCC Bandar Lampung ${ }^{12}$ \\ J1. Cut Nyak Dien No. 65 Bandar Lampung, 0721-250766 \\ Email : sukatmidcc@gmail.com, Rexa@gmail.com
}

\begin{abstract}
ABSTRAK
Lampung Timur sebagai salah satu Kabupaten di Lampung memiliki potensi alam dan budaya yang bisa dikembangkan sebagai objek wisata. Potensi tersebut antara lain alam yang indah dan hawa sejuk, dikelilingi oleh kehijauan bukit,gunung,dan pantai, banyak ditumbuhi aneka ragam bunga dan pohon. Oleh karena itu perlu dibangun sebuah website wisata yang ada di Lampung Timur guna memudahkan seseorang yang berminat untuk mengunjungi obyek wisata di daerah Lampung Timur.

Tujuan penelitian ini untuk menghasilkan sebuah sistem informasi geografis wisata Lampung Timur Pengembangan sistem yang digunakan adalah Extreme Programming.Alat perancangan sistem ini menerapkan Use Case Diagram, Class Diagram, Rancangan Input output Dn Activity Diagram. Bahasa Pemograman Yang digunakan PHP dan Database menggunakan MySql.
\end{abstract}

Hasil dari penelitian ini adalah sistem informasi geografis pariwisata yang dapat menampilkan peta wisata, rute wisata dan informasi tentang wisata itu sendiri.

Kata Kunci : Sistem Informasi Geografis, Extreme Programming, Use Case Diagram, Class Diagram, Activity Diagram, $P H P, M y S Q L$

\begin{abstract}
Lampung East as one district in Lampung has the potential of nature and culture that can be developed as. attraction. These include the potential beautiful natural and eve, cool surrounded by greenish, hill , mountain and the, many know all filled with flowers and trees. Therefore needs to be a website tourism in Lampung East to assist a person interested in visiting tourist attractions in the East Lampung.

The purpose of this research to produce a geographical information system tourism Lampung East system development used is extreme programming. Design system now applied use case, diagram class, diagram the input output dn activity. diagram. Programming language used PHP. and MySQL database.
\end{abstract}

The result of this research is geographical information system tourism can display, tourist map tourism route and information about. tourism itself .

Key word : Geographical information system, extreme programming, use case diagram, class diagram, activity diagram, $P H P, M y S Q L$

\section{PENDAHULUAN}

Perkembangan teknologi informasi dan komunikasi sudah dirasakan oleh hampir seluruh negara di dunia dari tahun ke tahun, perkembangan teknologi informasi dan komunikasi terus meningkat dengan sangat pesat. Disadari atau tidak, perkembangan teknologi informasi dan komunikasi ini telah membawa perubahan gaya hidup bagi setiap warga dunia yang mengalaminya. Perubahan hidup disini terjadi karena perkembangan teknologi informasi dan komunikasi yang terjadi 
ternyata memiliki dampak yang sangat signifikan bagi kehidupan manusia.

Pariwisata merupakan salah satu sumber pendapatan devisa terbesar dari setiap daerah. Penanganan dalam pengembangan pariwisata juga dipegang oleh pihak-pihak yang sesuai dengan bidangnya, agar dalam promosi dapat berhasil menarik wisatawan. Sekarang ini industri pariwisata berlomba-lomba menciptakan produk wisata yang bervariasi, menyangkut tentang pelestarian obyek wisata yang bertujuan untuk pengembangan obyek wisata untuk mengenalkan keindahan alam serta adat istiadat yang ada.

Lampung Timur sebagai salah satu Kabupaten di Lampung memiliki potensi alam dan budaya yang bisa dikembangkan sebagai objek wisata. Potensi tersebut antara lain alam yang indah dan hawa sejuk, dikelilingi oleh kehijauan bukit, gunung dan pantai, banyak ditumbuhi aneka ragam bunga dan pohon. Maka dari itu perlu dibangun sebuah website wisata yang ada di Lampung Timur guna memudahkan seseorang yang berminat untuk mengunjungi obyek wisata di daerah Lampung Timur.

\section{METODE PENELITIAN}

\subsection{Alat Perancangan}

\section{Use Case Diagram}

Use Case diagram adalah suatu urutan interaksi yang saling berkaitan antara sistem dan aktor. Use case dijalankan melalui cara menggambarkan tipe interaksi antara user suatu program (sistem) dengan sistemnya sendiri. Use case melalui sebuah cerita yang mana sebuah sistem itu dipakai. Use case juga dipakai untuk membentuk perilaku (behaviour) sistem yang akan dibuat. Sebuah use case menggambarkan sebuah interakasi antara pengguna (aktor) dengan sistem yang sudah ada.

\section{Class Diagram}

Diagram kelas merupakan diagram yang penting dalam pemodelan berorientasu objek. Diagram kelas membantu visualisasi struktur kelas dari suatu sistem dan hubungan diantaranya serta penjelasan detail dari tiap kelas tersebut. Diagram kelas digunakan untuk menampilkan kelas-kelas atau paket-paket dalam sistem dan relasi antar mereka. Biasanya, dibuat beberapa diagram kelas untuk satu sistem. Satu diagram kelas menampilkan subset dari kelas-kelas dan relasinya. Diagram kelas lainnya, mungkin menampilkan kelas-kelas termasuk atribut dan operasi dari kelas-kelas pembentuk diagram. Sedangkan diagram kelas yang lainnya lagi, mungkin menampilkan paket-paket kelas dan relasi antar paket

\section{Activity Diagram}

Pada dasarnya, diagram aktivitas adalah diagram flowchart yang diperluas yang menunjukkan aliran kendali satu aktivitas ke aktivitas lain. Kita menggunakan diagram ini untuk memodelkan aspek dinamis sistem. Activity Diagram adalah teknik untuk menggambarkan satu aktivitas ke aktivitas lain yang terjadi didalam usecase diagram.

\subsection{Metode Pengembangan Extreme Programming (XP)}

Extreme Programming (XP) merupakan sebuah proses rekayasa perangkat lunak yang cenderung menggunakan pendekatan berorientasi objek dan sasaran dari metode ini adalah tim yang dibentuk dalam skala kecil sampai medium serta metode ini juga sesuai jika tim dihadapkan dengan requirement yang tidak jelas maupun terjadi perubahan-perubahan requirement yang sangat cepat. Adapun tahapan pembangunan aplikasi web seleksi peserta pelatihan kerja dengan XP adalah sebagai berikut:

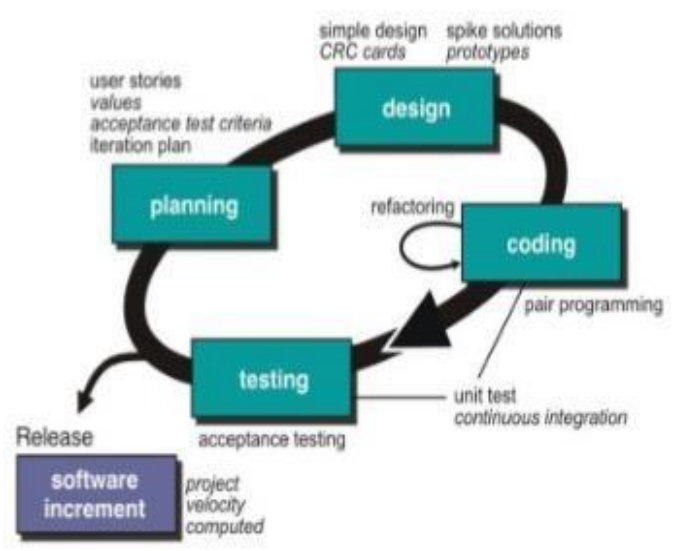

Gambar 1. Tahapan Extreme Progrqmming

1. Planning(Perencanaan) Tahapan ini dimulai dengan mendengarkan kumpulan kebutuhan aktifitas suatu sistem yang 
memungkinkan pengguna memahami proses bisnis untuk sistem dan mendapatkan gambaran yang jelas mengenai fitur utama, fungsionalitas dan keluaran yang diinginkan. Dalam pembangunan aplikasi web seleksi peserta pelatihan kerja pada tahapan ini dimulai dari mengidentifikasi permasalahan yang timbul pada sistem yang sedang berjalan, kemudian dilakukan analisakebutuhan pengguna terhadap sistem yang akan dibangun.

2. Design(Perancangan) Pada tahapan perancangan dilakukan pembuatan pemodelan sistem berdasarkan hasil analisa kebutuhan yang didapatkan. Selain itu dibuatkan juga pemodelan basis data untuk menggambarkan hubungan antar data. Pemodelan sistem yang digunakan yaitu Unified Modelling Language (UML) yang terdiri dari beberapa diagram antara lain Use-Case Diagram, Activity Diagram, Component Diagram dan Deployment Diagram. Sedangkan untuk pemodelan basis data menggunakan Entity Relationship Diagram (ERD) dan Logical Record Structure (LRS).

3. Coding(Pengkodean)Tahapan ini merupakan implementasi dari perancangan model sistem yang telah dibuat kedalam kode program yang menghasilkan prototipe dari perangkat lunak. Dalam pembangunan aplikasi web seleksi peserta pelatihan kerja menggunakan bahasa pemrograman PHP yang dikombinasikan dengan HTML, CSS dan Javascript. Untuk implementasi basis data, Database Management System yang digunakan adalahMySQL.

4. Testing(Pengujian)Tahapan ini merupakan tahapan pengujian terhadap aplikasi yang sudah dibangun, pada tahapan ini ditentukan oleh pengguna sistem dan berfokus pada fitur dan fungsionalitas dari keseluruhan sistem kemudian ditinjau oleh pengguna sistem. Metode yang digunakan dalam melakukan pengujian terhadap aplikasi web seleksi peserta pelatihan kerja adalah Black-Box Testing dengan melakukan pengujian terhadap masukkan dan keluaran yang dihasilkansistem.+
Adapun data-data yang didapat dari penelitian untuk adala $\mathrm{h}$ terdapat 11 lokasi wisata yang tersebar di wilayah Kabupaten Lampung Timur.

\subsection{Design}

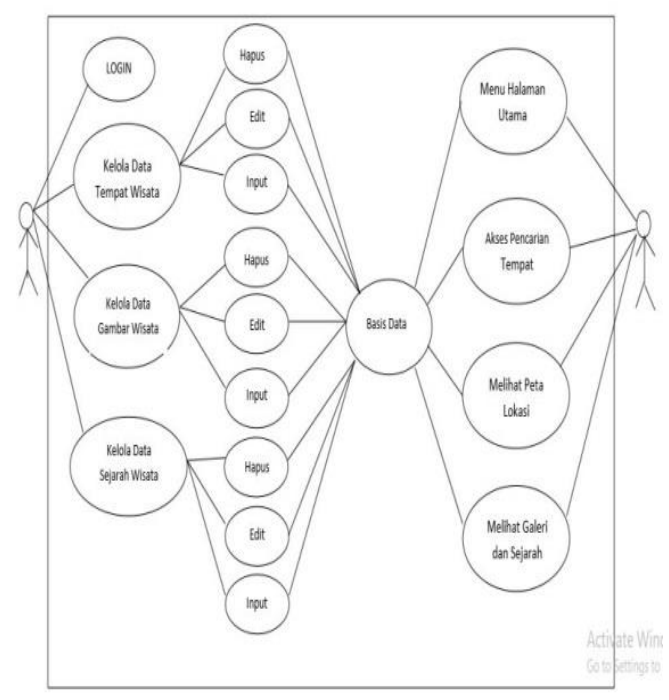

Gambar 2. Use Case Diagram

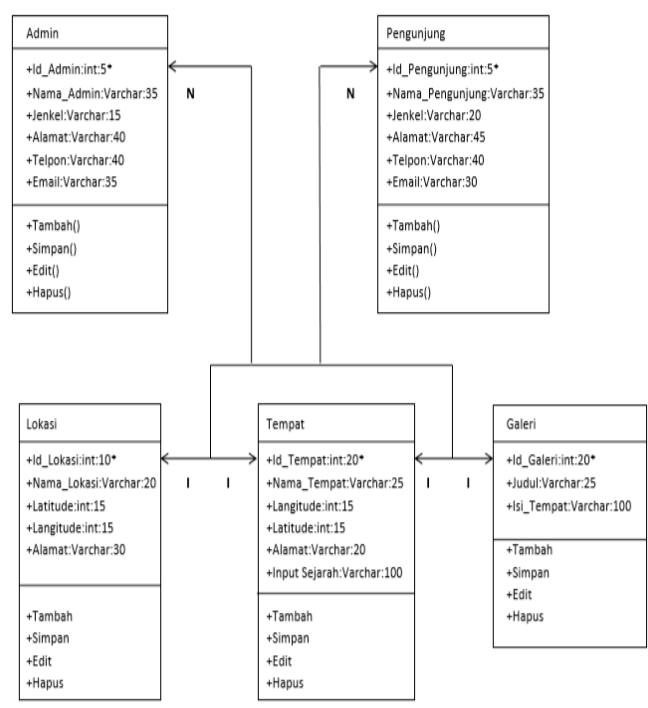

Gambar 3. Class Diagram

\section{HASIL PEMBAHASAN}

\subsection{Planning}



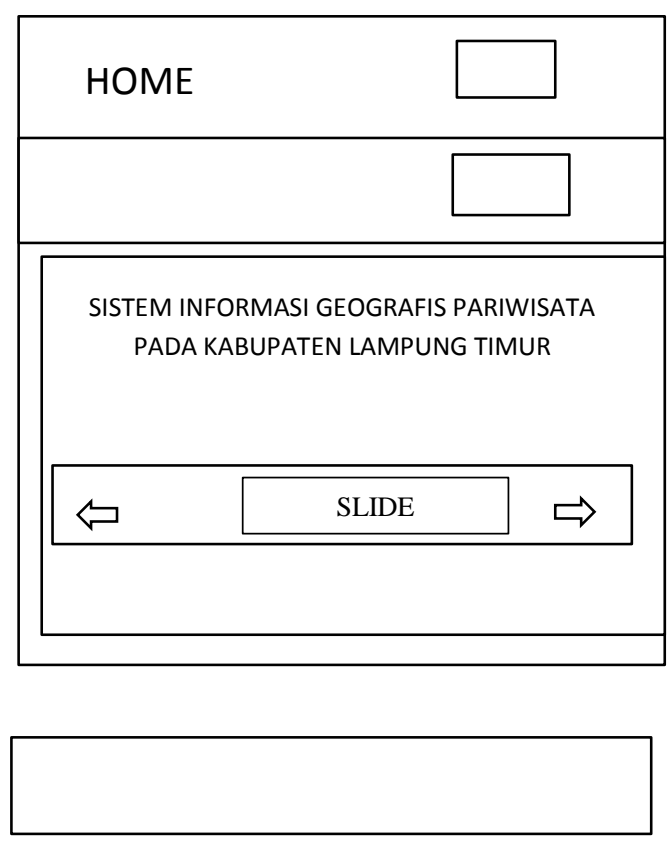

\section{TEMPAT}

Pencarian

Alamat wisata

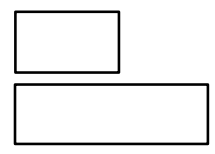

Sele

PETA PARIWISATA LAMPUNG

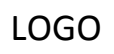

HOME

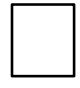

Rute

Detail

Total Jarak

Peta

GPS

Pengunjun

Gambar 6. Rancangan Lokasi Wisata

\section{Activity Diagram Login}

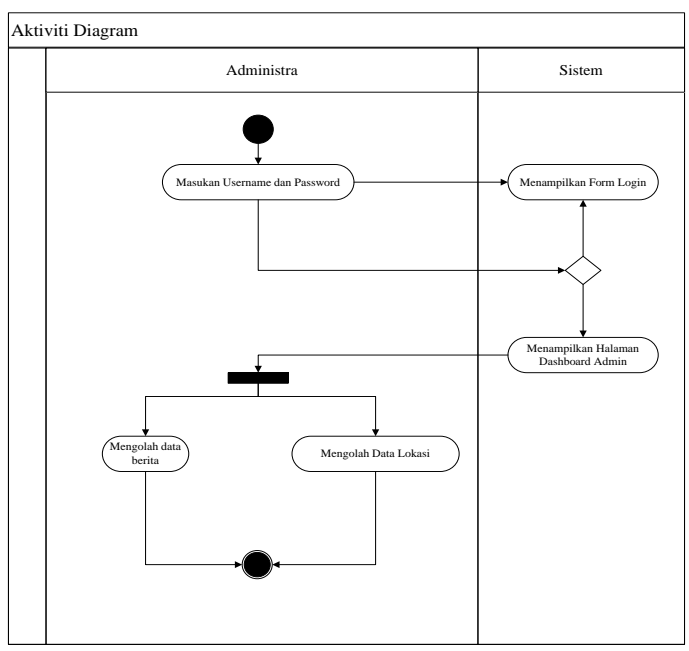

Gambar 7. Activity Diagram Login

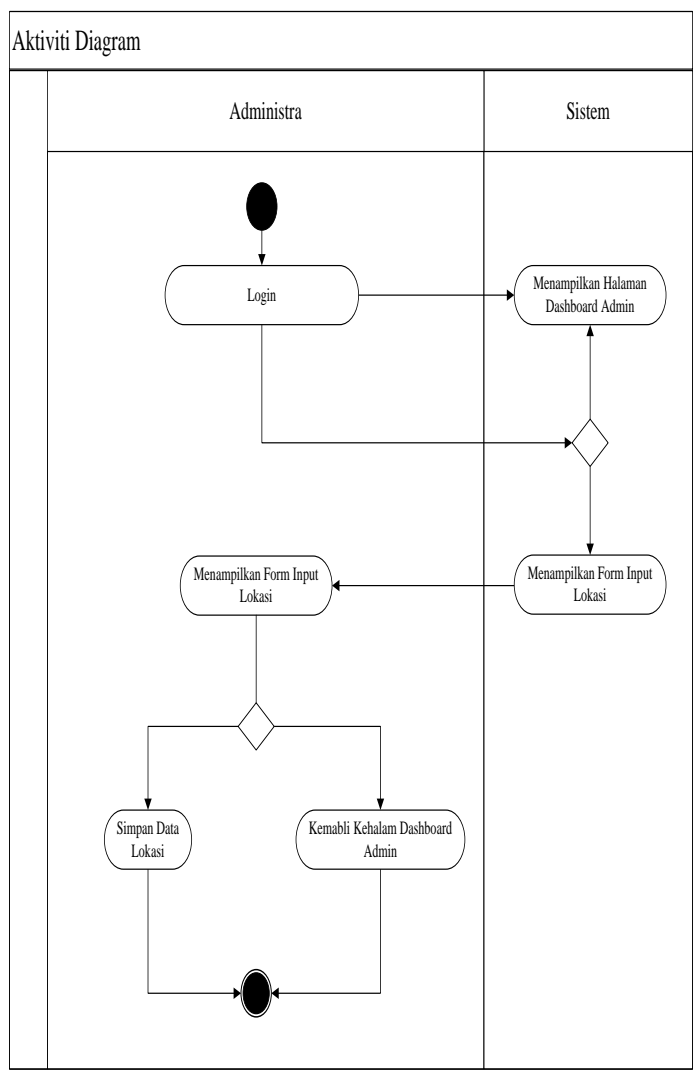

Gambar 8. Activity Diagram Tempat Wisata 


\section{Activity Diagram Pengunjung}

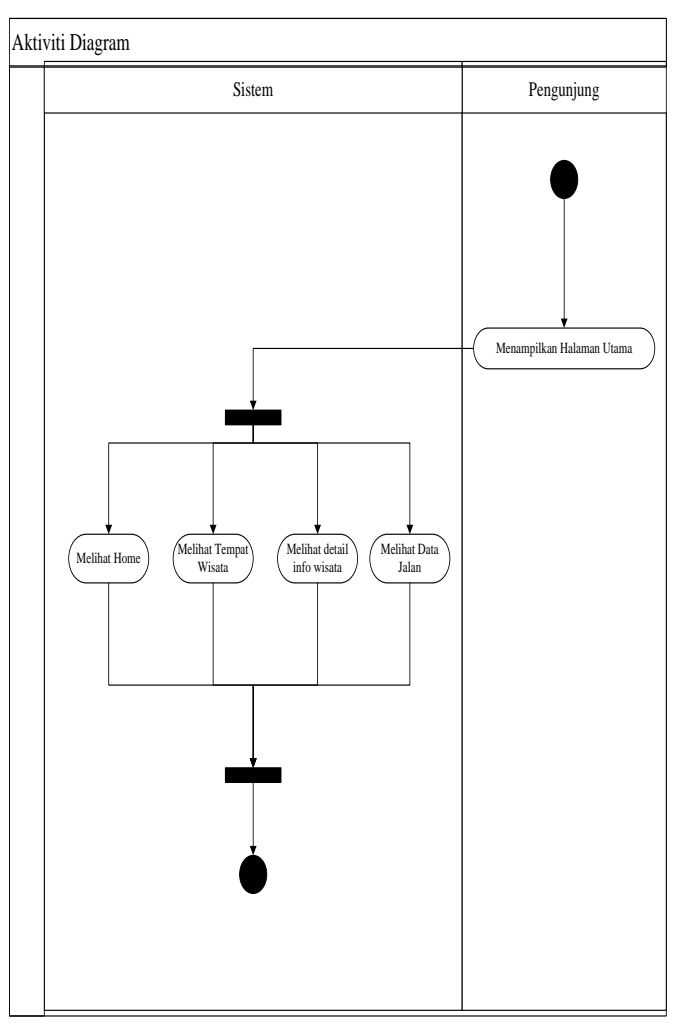

Gambar 9. Activity Diagram Pengunjung

\subsection{Coding}

Selanjutnya rancangqn diimplementasikan kedealam bahasa pemrograman dengan hasil program sebagai berikut.

\section{Tampilan Login.}

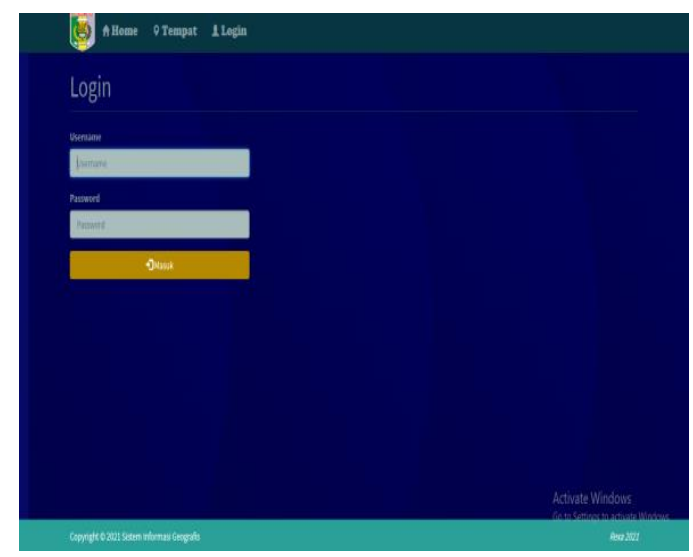

Gambar 10. Tampilan halaman login

\section{Halaman Utama}

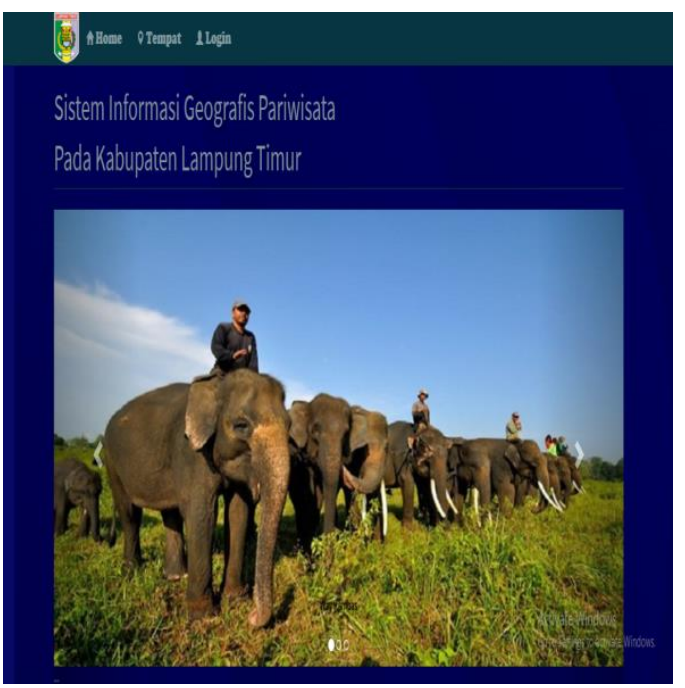

Gambar 11. Tampilan halaman utama

\section{PetaWisata}

Untuk halaman tempat ini pengunjung langsung bisa melihat peta wisata, sejarah wisata, informasi seputar wisata dan rute wisata, pengunjung bisa langsung mencari wisata yang diinginkan dengan cara mengklik pencarian dengan menulisakan nama wisatanya

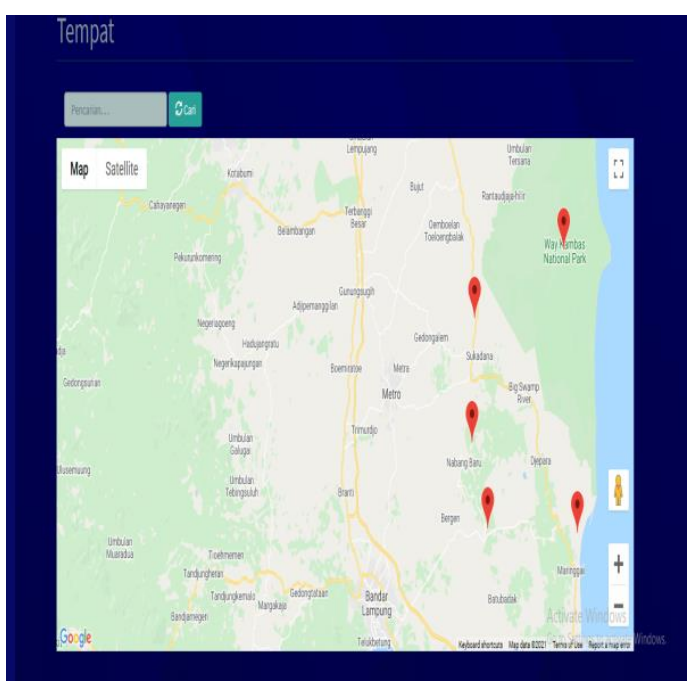

Gambar 12. Tampilan peta lokasi wisata

Selanjutnya jika pengunjung ingin langsung di arahkan ke tempat wisata yang di inginkan dan dapat melihat jalur/rute nya bisa langsung 
mengklik rute detail dan akan muncul tampilan seperti berikut.

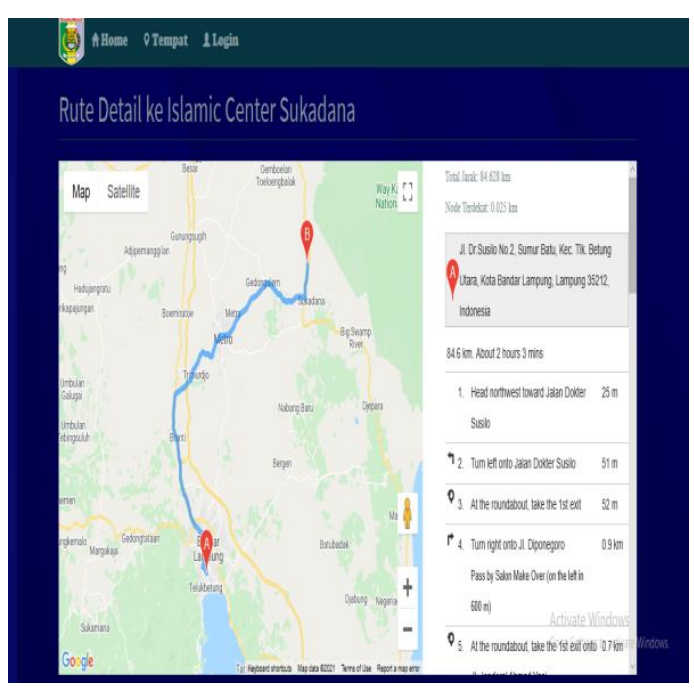

Gambar 13. Tampilan detail lokasi wisata dan informasinya

\subsection{Testing}

Tahap terakhir adalah dilaksnakan pengujian terhadap rancangan dan program. dari proses pengujian diperoleh hasil bahwa rancangan sudah dibuat sesuai kebutuhan dan program yang dihasilkan sesuai dengan rancangan yang telah dibuat dan disepakati bersama.

\section{PENUTUP}

Sistem Informasi Geografis kabupaten Lampung Timur yang dihasilkan dapat memberikan informasi mengenai lokasi wisata yang disertai dengan peta lokasi berikut informasi dan sejarah tentang wisata yang bersangkutan. Hal ini tentu saja membantu calon wisatawan yang ingin mengunjungi objek wisata di Kabupaten Lampung Timur. Dan pada akhirnya dapat memajukan wisata di Kabupaten Lampung Timur.

\section{DAFTAR PUSTAKA}

[1] Abu Nizam Faisal, 2016, SISTEM INFORMASI GEOGRAFIS BERBASIS WEB UNTUK PENYEBARAN FASILITAS UMUM DI KABUPATEN KLATEN. Jurnal Program Studi Teknik Informatika. Surakarta, Indonesia.
[2] Adnyana, Efendi, 2014 "RANCANG BANGUN SISTEM INFORMASI GEOGRAFIS PERSEBARAN LOKASI OBYEK PARIWISATA BERBASIS WEB DAN MOBILE ANDROID (STUDI KASUS DI DINAS PARIWISATA KABUPATEN GIANYAR)" Jurnal Teknologi Informasi dan Komunikasi, ISSN : 2087 - 0868, Volume 5 Nomor 1 Maret 2014.

[3] Ardhana Kusuma Murya Yosef, 2017 RANCANG BANGUN SISTEM INFORMASI GEOGRAFI BERBASIS ANDROID PEMETAAN FASILITAS AUTOMATED TELLER MACHINE MENGGUNAKAN GOOGLE MAPS API DAN METODE UJI PRODUK ISO 9126, Yogyakarta : 2017

[4] Hamidi, 2016, SISTEM INFORMASI GEOGRAFI BERBASIS WEB PENYEBARAN DANA BANTUAN OPERASIONAL SEKOLAH, Jurnal Masyarakat Informatika, Volume 2, Nomor 3, ISSN 2086 - 4930

[5] Minarni dan Yusdi, Yovie febri, 2015, "SISTEM INFORMASI GEOGRAFIS PARIWISATA KOTA PADANG MENGGUNAKAN

APPLICATION PROGRAMMING INTERFACE (API) GOOGLE MAPS BERBASIS WEB" Vol. 3 No. 1 April 2015 Jurnal TEKNOIF ISSN: 2338-2724.

[6] Moh.Aghus Husainidan Wahyu Dwi, 2017, SISTEM INFORMASI GEOGRAFIS (SIG) PEMETAAN SEKOLAH BERBASIS WEB DI KECAMATAN WONODADI KABUPATEN BLITAR, Jurnal Ilmiah Teknik Informatik, 2017. 